\title{
Molecular morphology and function of bull spermatozoa linked to histones and associated with fertility
}

\author{
Rodrigo V de Oliveira ${ }^{1,2}$, Sule Dogan ${ }^{1}$, Lauren E Belser ${ }^{1}$, Abdullah Kaya $^{3}$, Einko Topper ${ }^{3}$, \\ Arlindo Moura ${ }^{2}$, Giselle Thibaudeau ${ }^{4}$ and Erdogan Memili ${ }^{1}$ \\ ${ }^{1}$ Functional Genomics of Animal Reproduction and Development, Department of Animal and Dairy Sciences, \\ Mississippi State University, 4025 Wise Center, Mississippi State, Mississippi 39762, USA, ${ }^{2}$ Department of Animal \\ Sciences, Federal University of Ceara, Fortaleza, Ceara 60021-970, Brazil, ${ }^{3}$ Alta Genetics, Incorporated Alta Genetics, \\ Inc., Watertown, Wisconsin 53094, USA and ${ }^{4}$ Institute for Imaging and Analytical Technologies, Mississippi State \\ University, Mississippi State, Mississippi 39762, USA
}

Correspondence should be addressed to E Memili; Email: em149@ads.msstate.edu

\begin{abstract}
Sub-par fertility in bulls is influenced by alterations in sperm chromatin, and it might not be solved with increased sperm concentration in artificial insemination. Appropriate histone retention during sperm chromatin condensation plays critical roles in male fertility. The objective of this study was to determine failures of sperm chromatin condensation associated with abnormal persistence or accessibility of histones by aniline blue (ANBL) test, expression levels, and cellular localizations of one variant and two core histones (H3.3, H2B, and $\mathrm{H} 4$ respectively) in the spermatozoa of low-fertility (LF) vs high-fertility (HF) bulls. The expression levels and cellular localizations of histones in spermatozoa were studied using immunoblotting, immunocytochemistry, and staining methods. The bioinformatics focused on the sequence identity and evolutionary distance of these proteins among three mammalian species: bovine, mouse, and human. We demonstrated that ANBL staining was different within the $\operatorname{LF}(1.73(0.55,0.19))$ and $H F(0.67(0.17,0.06))$ groups $(P<0.0001)$, which was also negatively correlated with in vivo bull fertility $(r=-0.90, P<0.0001)$. Although these histones were consistently detectable and specifically localized in bull sperm cells, they were not different between the two groups. Except $\mathrm{H} 2 \mathrm{~B}$ variants, $\mathrm{H} 3.3$ and $\mathrm{H} 4 \mathrm{showed}$ $\mathbf{1 0 0} \%$ identity and were evolutionarily conserved in bulls, mice and humans. The H2B variants were more conserved between bulls and humans, than in mice. In conclusion, we showed that $\mathrm{H} 2 \mathrm{~B}, \mathrm{H} 3.3$, and $\mathrm{H} 4$ were detectable in bull spermatozoa and that sperm chromatin condensation status, changed by histone retention, is related to bull fertility.
\end{abstract}

Reproduction (2013) 146 263-272

\section{Introduction}

Fertility is one of the most important factors influencing mammalian reproduction and development. Bull fertility is defined as the ability of the sperm to fertilize and activate the egg, to sustain embryonic development, and is usually evaluated by determining sperm characteristics such as motility and morphology (Correa et al. 1997). Although there are several approaches to evaluate capacitation status and membrane integrity using microscopy and/or flow cytometry in sperm cells, these techniques may still not be sufficient to predict overall male fertility (Januskauskas et al. 1999, Puglisi et al. 2012). One of the reasons for the failure of the aforementioned studies is that they primarily focused on the traits that are necessary for spermatozoa to reach and fertilize the oocyte, while ignoring other traits that are essential for egg activation and to support early embryonic development (Silva \& Gadella 2006). In addition to these traits, sperm chromatin integrity is also essential for proper sperm physiology and early embryonic development. For example, studies have revealed that sperm chromatin damage reduces fertility in bulls (García-Macías et al. 2007) and in human males (Agarwal \& Said 2003). More precisely, abnormal levels of specific nucleoproteins such as protamines (Simon et al. 2011) and $\mathrm{H} 4$ acetylation (Sonnack et al. 2002) in spermatozoa have been found to be associated with human subfertility. The molecular alterations leading to sub-par fertility have also been demonstrated to be important in cattle industry because they are not compensated for by increasing the amounts of spermatozoa used in artificial insemination (Al; Blaschek et al. 2011).

The chromatin in mature spermatozoa is composed of DNA wrapped around the nucleoproteins, mainly protamines, but also some histones (D'Occhio et al. 2007). Following spermatogenesis, histone-protamine transition takes place during spermiogenesis where histones from early spermatids are subsequently and 
partially substituted by transition proteins and, finally, they are almost completely replaced by protamines at later stages (Hales et al. 2011). Although the histoneassociated sperm DNA is $<15 \%$ in humans (Gatewood et al. 1990), it is suggested that this histone retention provides less condensed DNA regions where paternal genes can be more accessible to transcription factors right after fertilization (Rajender et al. 2011). The four types of core (canonical) histones involved in DNA packaging are $\mathrm{H} 2 \mathrm{~A}, \mathrm{H} 2 \mathrm{~B}, \mathrm{H} 3$, and $\mathrm{H} 4$ nucleoproteins, and they form a tightly coiled packed structure along with protamines, called the toroidal model (Dadoune 1995). Although proper histone retention is believed to be vital for the genes that will be activated before and/or after fertilization, an excessive ratio of histone retention occasionally indicates sperm chromatin immaturity and this ultimately causes sperm dysfunctions. In general, the evaluation of excessive histone retention, i.e. sperm chromatin immaturity, can be carried out using several cost-effective methods such as the chromomycin A3, toluidine blue, and aniline blue (ANBL) staining methods (Agarwal \& Said 2003). Since histones are rich in lysine, the ANBL dye attaches to nucleohistones and generates a blue color in the sperm head (Franken et al. 1999). Posttranslational modifications (PTMs) such as methylation, acetylation, and phosphorylation of histones can epigenetically influence the accessibility of the male genome to maternal transcription factors during embryonic development (Miller et al. 2010).

Methylated histones are mainly found in heterochromatin regions where the genes are occasionally silenced (Fischle et al. 2003), whereas acetylation of histones is strongly associated with the euchromatin architecture, reducing histone-DNA links and facilitating both replacement of protamines and activation of transcription (Struhl 1998) during spermatogenesis (Dadoune 2003). The phosphorylation of serine residues in histones is also commonly associated with gene activation (Prigent \& Dimitrov 2003). Interestingly, H2B variants have been shown to be highly expressed during DNA damage and infertility in humans (Zini et al. 2008). In addition to H2B, $\mathrm{H} 3$ and its replacement variant $\mathrm{H} 3.3$ have been demonstrated to be associated with gene activation (Mito et al. 2005). Specific PTMs in H3 are localized in the regions of sperm genome that are active during spermatogenesis and early embryonic development (Brykczynska et al. 2010, Steilmann et al. 2011). Lastly, $\mathrm{H} 4$ is associated with the success of chromatin remodeling during spermatogenesis (Kleiman et al. 2008) and male inheritance of chromosomal architecture during zygote development (van der Heijden et al. 2006).

However, the extent of cellular and molecular associations between expression levels and PTMs of histones that influence bull fertility is not known. Furthermore, the molecular mechanisms of those events that regulate male fertility remain a mystery. Therefore, there is a need for research to elucidate the interconnectedness between histones in spermatozoa and male fertility at the molecular and cellular levels. The objective of this study was to determine sperm chromatin status, expression levels, and cellular localizations of histones in the sperm cells of highfertility (HF) vs low-fertility (LF) bulls by taking advantage of bioinformatics. Specifically, we studied the expression levels and cellular localizations of $\mathrm{H} 3.3, \mathrm{H} 2 \mathrm{~B}$, and $\mathrm{H} 4$ in the sperm cells of bulls with varying fertility.

\section{Materials and methods \\ Determination of bull fertility}

The prediction of bull fertility scores was done according to the Alta Advantage Program (Alta Genetics, Inc., Watertown, WI, USA), which is periodically updated by information from partnering herds (Peddinti et al. 2008). All factors influencing fertility performance of the sires such as the environmental and herd management were adjusted using reliable threshold models by Zwald et al. (2004a, 2004b). Fertility estimation with the related parameters was done using the Probit F90 Software developed by Chang et al. (2004) (Department of Dairy Science, University of Wisconsin, Madison, WI, USA). The database calculates the fertility of each sire based on the average conception of more than 300 breeding outcomes with the percent deviation of the conception rates. According to this calculation, the S.D. of the population was used as the criterion to classify the fertility of bulls, where HF and LF bulls had a 2 s.D. difference from the mean. Therefore, the HF bulls were 4 s.D. different from their LF counterparts, leading to extreme outliers for the given population.

\section{Isolation of spermatozoa}

The frozen semen samples with their fertility scores were provided by Alta Genetic, Inc. (Table 1). In this study, sixteen

Table 1 Fertility phenotypes of the sixteen bulls. Bulls $1-8$ are from the LF group and bulls 9-16 are from the HF group. The bulls are individually represented with their fertility scores and the number of breeding. Fertility score was calculated using the Probit F90 Software, and it is expressed as the percent deviation of each conception rate from the average conception rate of all the bulls.

\begin{tabular}{lcc}
\hline Bull number & Fertility score & Number of breeding \\
\hline Low-fertility bulls & & \\
1 & -12.3 & 595 \\
2 & -8.1 & 1552 \\
3 & -7.2 & 719 \\
4 & -6.4 & 668 \\
5 & -6.3 & 750 \\
6 & -5.9 & 781 \\
7 & -5.6 & 702 \\
8 & -4.2 & 783 \\
High-fertility bulls & & \\
9 & 3.3 & 1024 \\
10 & 4.2 & 651 \\
11 & 4.5 & 578 \\
12 & 4.8 & 300 \\
13 & 4.8 & 300 \\
14 & 4.8 & 518 \\
15 & 5.0 & 326 \\
16 & 6.2 & 743 \\
\hline
\end{tabular}


bulls were divided into two groups based on their fertility scores. Semen straws were thawed at $37^{\circ} \mathrm{C}$ for $30 \mathrm{~s}$, and spermatozoa were first washed with $2 \mathrm{ml}$ of Percoll in PBS (D'Amours et al. 2010) and then washed twice with $5 \mathrm{ml}$ of PBS (pH 7.4) containing a protease inhibitor cocktail (cOmplete, EDTA-free Protease Inhibitor Cocktail, Roche) at $800 \mathrm{~g}$ for $5 \mathrm{~min}$. Later, only sperm pellets were stored at $-80^{\circ} \mathrm{C}$ for immunoblotting; otherwise, they were used immediately following isolation in the ANBL staining and immunocytochemistry experiments.

\section{ANBL test}

Smears of the washed sperm were prepared on glass slides and air-dried. Then, the smears were fixed with $3 \%$ of glutaraldehyde (PBS, pH 7.4) for $30 \mathrm{~min}$ at room temperature (RT). Following fixation, the smears were washed with PBS twice for 5 min each. The smears were then stained in $5 \%$ of ANBL in $4 \%$ acetic acid ( $\mathrm{pH} 3.5$ ) for $7 \mathrm{~min}$, washed once more with PBS (pH 7.4), and allowed to air-dry. Later, 200 spermatozoa were evaluated per slide (in duplicate) under the $1000 \times$ oil immersion objective. Unstained spermatozoa were considered normal and dark blue as sperm cells with failures of chromatin condensation (immature sperm cells) related to excessive retention (Dadoune et al. 1988, Dadoune 2003) or accessibility (de Lamirande et al. 2012) of sperm histones.

\section{Extraction of sperm nucleoproteins}

The nucleoproteins were extracted according to the method of de Yebra \& Oliva (1993). In order to lyse the cells, sperm pellets with $5 \times 10^{7}$ cells were washed twice with $400 \mu \mathrm{l}$ of $1 \mathrm{mM}$ phenylmethylsulfonyl fluoride (PMSF) in $\mathrm{ddH}_{2} \mathrm{O}$. Then, $100 \mu \mathrm{l}$ of $20 \mathrm{mM}$ EDTA, $1 \mathrm{mM}$ PMSF, and $100 \mathrm{mM}$ Tris ( $\mathrm{pH}$ 8.0) were added to the pellets followed by the addition of $100 \mu \mathrm{l}$ of $6 \mathrm{M}$ guanidine hydrochloride, $575 \mathrm{mM}$ dithiothreitol (DTT), and $200 \mu \mathrm{l}$ of $552 \mathrm{mM}$ sodium iodoacetate. The samples were protected from light and incubated at $20{ }^{\circ} \mathrm{C}$ for $30 \mathrm{~min}$. To the samples, $1000 \mu \mathrm{l}$ of ethanol pre-equilibrated at $-20^{\circ} \mathrm{C}$ were added, and each sample was then incubated at $-20^{\circ} \mathrm{C}$ for $1 \mathrm{~min}$ and centrifuged for 15 min twice. The pellet was incubated with $1000 \mu \mathrm{l}$ of $0.5 \mathrm{M} \mathrm{HCl}$ at $37^{\circ} \mathrm{C}$ for $15 \mathrm{~min}$ and then centrifuged at RT for $10 \mathrm{~min}$. The supernatant was held, and $300 \mu \mathrm{l}$ of $100 \%$ trichloroacetic acid (TCA) at $4{ }^{\circ} \mathrm{C}$ were added. Following $5 \mathrm{~min}$ of incubation at $4{ }^{\circ} \mathrm{C}$, the samples were centrifuged at $4{ }^{\circ} \mathrm{C}$ for $10 \mathrm{~min}$. The protein pellet was washed twice with $500 \mu \mathrm{l}$ of $1 \%$ 2-mercaptoethanol in acetone, dried, dissolved in $100 \mu \mathrm{l}$ of $5.5 \mathrm{M}$ urea, 20\% 2-mercaptoethanol, and 5\% acetic acid, and stored at $-80^{\circ} \mathrm{C}$.

\section{Western blotting}

Protein concentration was measured using the Micro BCA Protein Assay Kit (cat \#23235, Pierce, Rockford, IL, USA). Sperm nucleoproteins were separated using acetic acid-urea PAGE. The $13.3 \times 8.7 \times 0.1 \mathrm{~cm}$ gel was composed by $7.5 \%$ stacking/15\% separating (0.9 $\mathrm{M}$ acetic acid, $2.5 \mathrm{M}$ urea, $2 \%$ ammonium persulfate (APS), and $0.9 \%$ tetramethylethylenediamine (TEMED)). To each sample, one-half its volume of loading buffer (5.5 M urea, 20\% 2-mercaptoethanol, 5\% acetic acid, $50 \%$ glycerol, and $0.2 \%$ methylene blue) was added. The electrophoresis was performed in $0.9 \mathrm{M}$ acetic acid buffer at $130 \mathrm{~V}$ for $80 \mathrm{~min}$. The proteins were then transferred on to a PVDF membrane (Immobilon-P) using a semidry electroblotter (HEP-1, OWL) and 2.5\% acetic acid buffer. Subsequently, the membrane was incubated in TBS/1\% casein (cat \#1610782, Bio-Rad) at RT for $1 \mathrm{~h}$. The blocked membrane was then incubated with a rabbit primary antibody solution $(\mathrm{H} 2 \mathrm{~B}, \mathrm{H} 3.3$, or H4; Abcam Ab1790, Ab97968 and Ab10158 respectively, at $4{ }^{\circ} \mathrm{C}$ overnight; Abcam, Cambridge, MA, USA). Thereafter, the membrane was washed thrice with TBS and $0.1 \%$ Tween 20 at RT for 10 min each. Incubation with the secondary antibody solution (anti-rabbit IgG conjugated with HRP, Santa Cruz \#sC2313) diluted $1 / 50000$ in TBS-0.1\% Tween 20 was performed at RT for $1 \mathrm{~h}$. Following three washes with TBS $+0.1 \%$ Tween 20, the proteins were detected using a chemiluminescent HRP substrate (Immobilon Western, cat \#P36599), and the expression signals were determined on a ChemiDoc XRS System (Bio-Rad; cat \#170-8070) with the Quantity One Software (Bio-Rad).

\section{Immunocytochemistry}

To locate and measure the expression of specific histones in the spermatozoa, we carried out immunocytochemistry experiments adapted from the protocols described by Li et al. (2008) with modifications. The spermatozoa were washed with PBS containing a protease inhibitor (cOmplete, Roche) and $10 \mathrm{mM}$ EDTA. After washing, the cells were incubated with $20 \mathrm{mM}$ CHAPS for 20 min at RT and washed once with PBS only. In order to decondense sperm chromatin, the samples were incubated with $10 \mathrm{mM}$ DTT and $1 \mathrm{mg} / \mathrm{ml}$ of heparin at RT for $30 \mathrm{~min}$ (Motoishi et al. 1996). The spermatozoa were posteriorly treated and attached to poly-L-lysine-coated coverslips. The coverslip smears were fixed with $4 \%$ paraformaldehyde in PBS for 10 min at $4{ }^{\circ} \mathrm{C}$ and permeabilized with $0.2 \%$ Triton $\mathrm{X}-100$ and $0.1 \% \mathrm{BSA}$ in PBS for $15 \mathrm{~min}$ at RT. Next, the smears were subjected to a series of dehydration steps using 50, 70, 95, and 100\% ethanol respectively. Subsequently, fixation was done using $100 \%$ methanol for $20 \mathrm{~min}$ at $-20{ }^{\circ} \mathrm{C}$. Following one washing with a washing buffer (WB: PBS containing $0.1 \%$ Triton X-100), the samples were blocked with $1 \%$ BSA in the WB for $1 \mathrm{~h}$ at RT.

Rabbit polyclonal antibodies against H2B (1:250), H3.3 (1:250), and $\mathrm{H} 4 \quad(1: 250)$ (Abcam) were utilized at $4{ }^{\circ} \mathrm{C}$ overnight. Following two rounds of washes in the WB at RT for $15 \mathrm{~min}$, the coverslips were incubated with a secondary antibody solution (1:250; donkey anti-rabbit, DyLight 488, Abcam) with $2.5 \mu \mathrm{g} / \mathrm{ml}$ of DAPI at RT for $1 \mathrm{~h}$. Following a final wash in PBS with $2 \%$ Triton X-100 at RT for 15 min, the coverslips were sealed to the slides using a drop of an antifade mounting medium (VECTAshield, $\mathrm{H}$-1000). The slides were examined under a confocal fluorescence microscope (Zeiss LSM 510) with $1000 \times$ fold magnification using immersion oil. The images were analyzed using the LSM 510 Image Software and 100 spermatozoa, from two slides containing 50 sperm cells each, obtained from the LF and HF bulls were classified based on low, medium, and high histone signals. The area of decondensed sperm head $\left(\mu \mathrm{m}^{2}\right)$ was also measured. 


\section{Bioinformatics}

We compared the sequences of $\mathrm{H} 2 \mathrm{~B}, \mathrm{H} 3.3$, and $\mathrm{H} 4$ among the bovine, human, and mouse species using computational tools. The protein sequences of interest were first extensively searched and aligned using UniProt for the bovine, human, and mouse species (www.uniprot.org, UniProt (2012)) Since these mammalian $\mathrm{H} 2 \mathrm{~B}$ proteins have numerous clusters and variants in the UniProt database, we prealigned these $\mathrm{H} 2 \mathrm{~B}$ protein clusters of interest that are $90 \%$ identical among the mammals prior to the analysis. The multiple alignments were done using the Clustal X method (http://www.clustal.org), while phylogenetic trees were created using the neighbor joining method (Saitou \& Nei 1987) for each H2B, H3.3, and $\mathrm{H} 4$ protein in the UniProt database. (Supplementary Tables 1 and 2 and Supplementary Figs 1 and 2, see section on supplementary data given at the end of this article).

\section{Statistical analysis}

We used the statistical package SYSTAT 12 (SYSTAT Software, Inc., Chicago, IL, USA) to analyze the data. The results are expressed as means (S.D. and S.E.M.). In order to verify differences between the LF and HF groups, Student's $t$-test was used $(P<0.05)$. Pearson's correlation was used to establish the relationship between histone retention (ANBL test) or histone expression (western blotting) and bull fertility $(P<0.05)$.

\section{Results}

\section{ANBL test}

The ANBL test was utilized to assess sperm chromatin condensation by histone retention in the LF and HF bulls. The spermatozoa that stained blue represented the deficient condensation of chromatin (nuclear immaturity) with excessive persistent histones and the unstained spermatozoa were those with normal sperm chromatin (Fig. 1). There was a significant difference in positive cells between the LF $(1.73(0.55,0.19))$ and HF $(0.67$ $(0.17,0.06))$ groups $(P<0.0001)$. A linear regression and Pearson's correlation were used to analyze the relationship between the percentage of positive

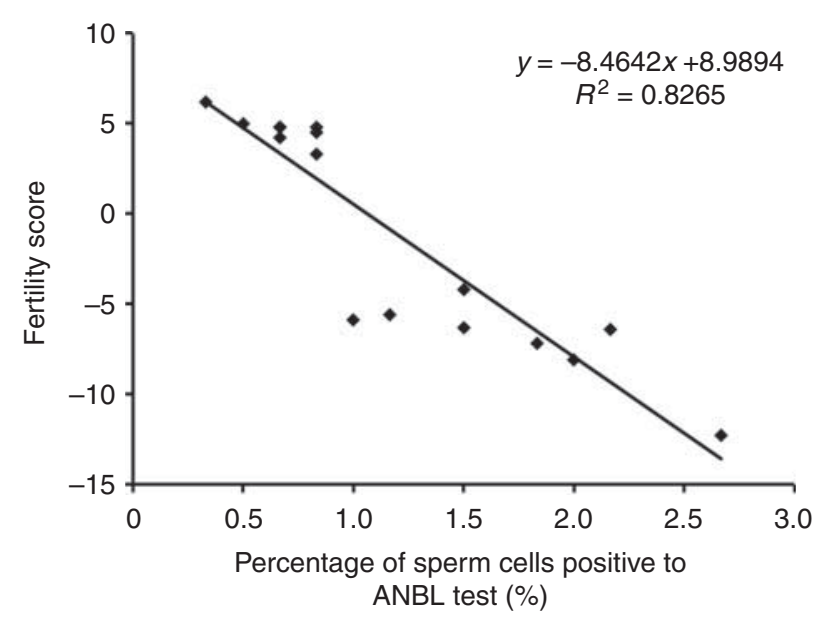

Figure 2 Linear regression analysis between aniline blue (ANBL) test results and fertility scores of the low- and high-fertility bulls. A negative and significant Pearson's correlation was found between the ANBL test results and fertility scores of the low- and high-fertility bulls $(r=-0.90, P<0.001)$.

spermatozoa and fertility index for each bull (Fig. 2). These parameters were negatively correlated to each other $\left(r=-0.90, r^{2}=0.82 ; P<0.0001\right)$.

\section{Western blotting}

We used an immunoblotting approach to evaluate the expression of $\mathrm{H} 2 \mathrm{~B}, \mathrm{H} 3.3$, and $\mathrm{H} 4$ in the sperm cells of bulls with varying fertility. Our results showed that the histones were consistently detectable in all the samples; however, we did not find any significant differences in histone levels in the sperm cells of the LF bulls compared with those of the HF bulls (Fig. 3). In addition, no correlation was found between the fertility index and western blotting results of $\mathrm{H} 2 \mathrm{~B}(P=0.98), \mathrm{H} 3.3$ $(P=0.84)$, and $\mathrm{H} 4(P=0.73)$.

\section{Immunocytochemistry}

We determined the localization of histones in the spermatozoa of the bulls with the lowest and highest

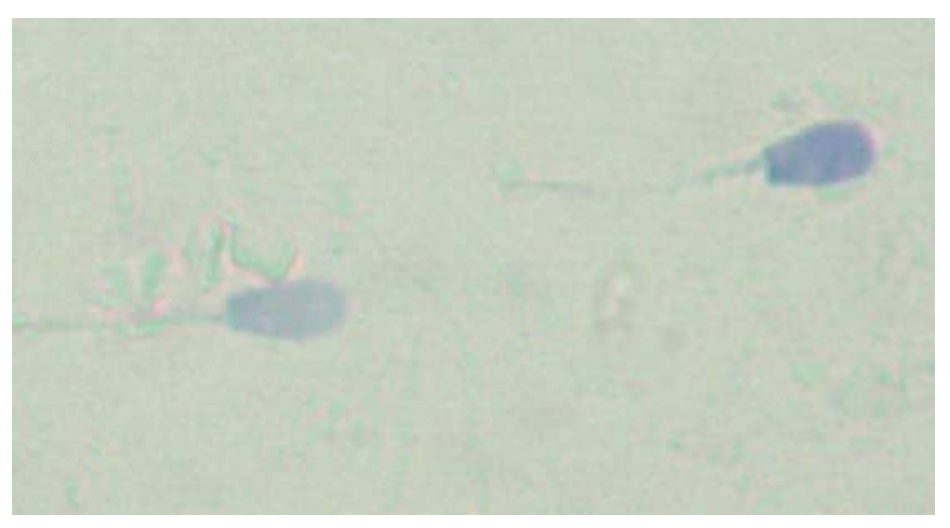

Figure 1 Bull sperm stained with aniline blue. The unstained sperm on the left has normal chromatin and the dark blue sperm on the right has abnormal chromatin condensation associated with retained and accessible histones. 
(a)

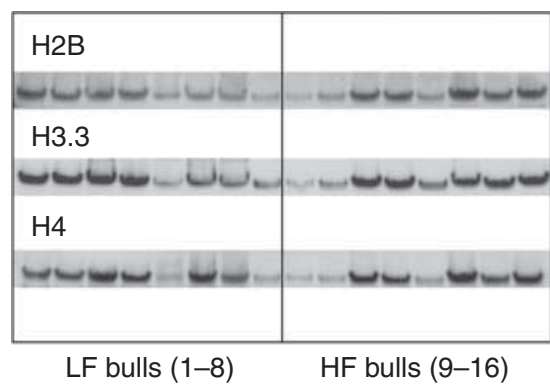

(c)

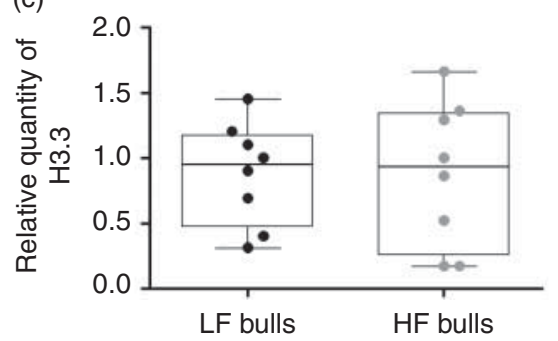

(b)

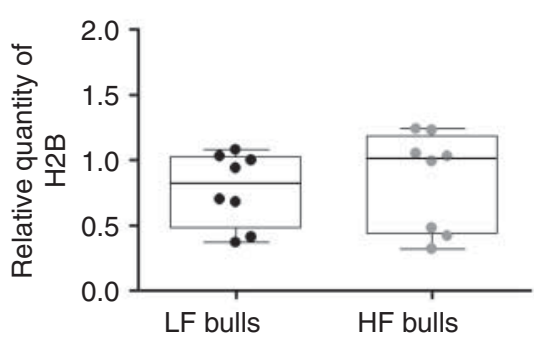

(d)

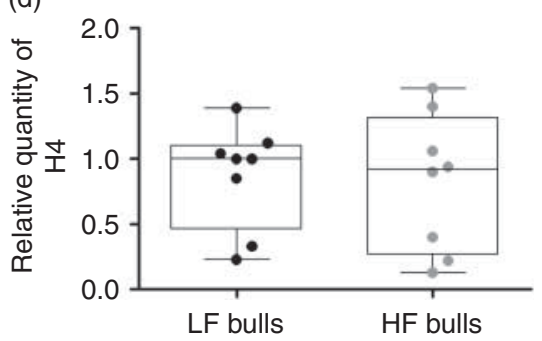

Figure 3 Western blot (a) and relative quantity of $\mathrm{H} 2 \mathrm{~B}$ (b), H3.3 (c), and H4 (d) in the low-fertility (LF; black dots) and high-fertility (HF; gray dots) groups. The relative quantity was obtained by calculating the ratio of the band intensity of each bull to that of bull 1 . The middle lines are medians, the edges of boxes are the 25th and 75th percentiles, and the whiskers are the minimum and maximum values. There were significant differences between the groups. fertility using immunofluorescence microscopy. The signals of histone proteins were clearly detectable in the sperm head (Fig. 4 B, C and D). These were present in the post-equatorial, equatorial and, predominantly, in the pre-equatorial region of the sperm head. We also observed histone fluorescence in the midpiece, probably from histones not associated with sperm chromatin. The mean values of total fluorescence intensity from histone signals and area of decondensed sperm head $\left(\mu \mathrm{m}^{2}\right)$ of 100 spermatozoa counted from each of the LF and HF bulls were $2.65 \times 10^{6}(1.70 ; 0.17), 2.60 \times 10^{6}(1.38$; $0.38), 77.56 \mu \mathrm{m}^{2}(13.80 ; 1.38)$ and $79.43 \mu \mathrm{m}^{2}(26.43$; $2.64)$, respectively. The counted sperm cells were divided into three classes (low, medium, and high levels of histone signals) with a range that was calculated by dividing the difference between maximum and minimum total fluorescence intensity values by 3 . The percentage, average of total fluorescence intensity, and area of decondensed sperm head of these spermatozoa with low, medium, and high degrees of histone retention are summarized in Table 2. Our immunocytochemistry results confirmed that the largest sperm population $(74.5 \%$, average from the two bulls) has a low level of histone retention. In addition, we found a positive correlation between the area of decondensed sperm head and the signal intensities of histones $(r=0.64 ; P<0.0001)$.

\section{Bioinformatics}

Using UniProt, we identified a total of 21 bovine H2B protein clusters, 12 of which were unique to the bovine species, while the remaining belonged to other mammalian members such as mice and humans. In total, 17 of $\mathrm{H} 2 \mathrm{~B}, 3$ of $\mathrm{H} 3.3$, and 3 of $\mathrm{H} 4$ proteins that belonged to bulls, mice and humans were used for further bioinformatics analysis. In detail, four mouse, seven human, and six bovine $\mathrm{H} 2 \mathrm{~B}$ protein sequences were selected for multiple alignments and phylogenetic trees. Bovine $\mathrm{H} 2 \mathrm{~B}$ variants $\mathrm{F} 2 \mathrm{Z} 4 \mathrm{E} 8$ and $\mathrm{A} 5 \mathrm{D} 7 \mathrm{~N} 2$ were $100 \%$ identical to their human counterparts Q99877 $(\mathrm{H} 2 \mathrm{~B} 1 \mathrm{~N})$ and Q16778 (H2B2E) based on the pairwise alignment; indeed, they were closely related to each other by having the common ancestral sequence based on our phylogenetic trees. Therefore, since bovine F2Z4F9, F2Z4E8, and A5D7N2 were $100 \%$ identical to human $\mathrm{H} 2 \mathrm{~B}$ type $1 \mathrm{~K}, \mathrm{H} 2 \mathrm{~B}$ type $1 \mathrm{~N}$, and $\mathrm{H} 2 \mathrm{~B}$ type $2 \mathrm{E}$, they should be considered as bovine $\mathrm{H} 2 \mathrm{~B} 1 \mathrm{~K}, \mathrm{H} 2 \mathrm{~B} 1 \mathrm{~N}$, and $\mathrm{H} 2 \mathrm{~B} 2 \mathrm{E}$. This is consistent with the results obtained from our pairwise alignments and phylogenetic trees. Besides, histone $\mathrm{H} 2 \mathrm{~B}$ type 1 was $100 \%$ conserved among the bovine (P62808), human (P62807), and mouse (Q6ZWY9) species, and they evolved from the common ancestral protein sequence (Supplementary Table 1 and Supplementary Fig. 1). On the other hand, bovine A5D7N2 showed $98.41 \%$ identity with human Q8N257 and mouse Q8CGP0 histone H2B type 3B, which were $100 \%$ conserved to each other. Besides, this $\mathrm{H} 2 \mathrm{~B}$ variant was evolutionarily more distant than its human and mouse counterparts. Only one protein variant of $\mathrm{H} 3.3$ and $\mathrm{H} 4$ per species was identified using the UniProt database, which was $100 \%$ identical and evolutionarily conserved among bulls, mice and humans based on multiple sequence alignments and phylogenetic trees (Supplementary Table 2 and Supplementary Fig. 2).

\section{Discussion}

Histones are thought to be present in sperm chromatin in a nonrandom distribution. Studies have demonstrated 

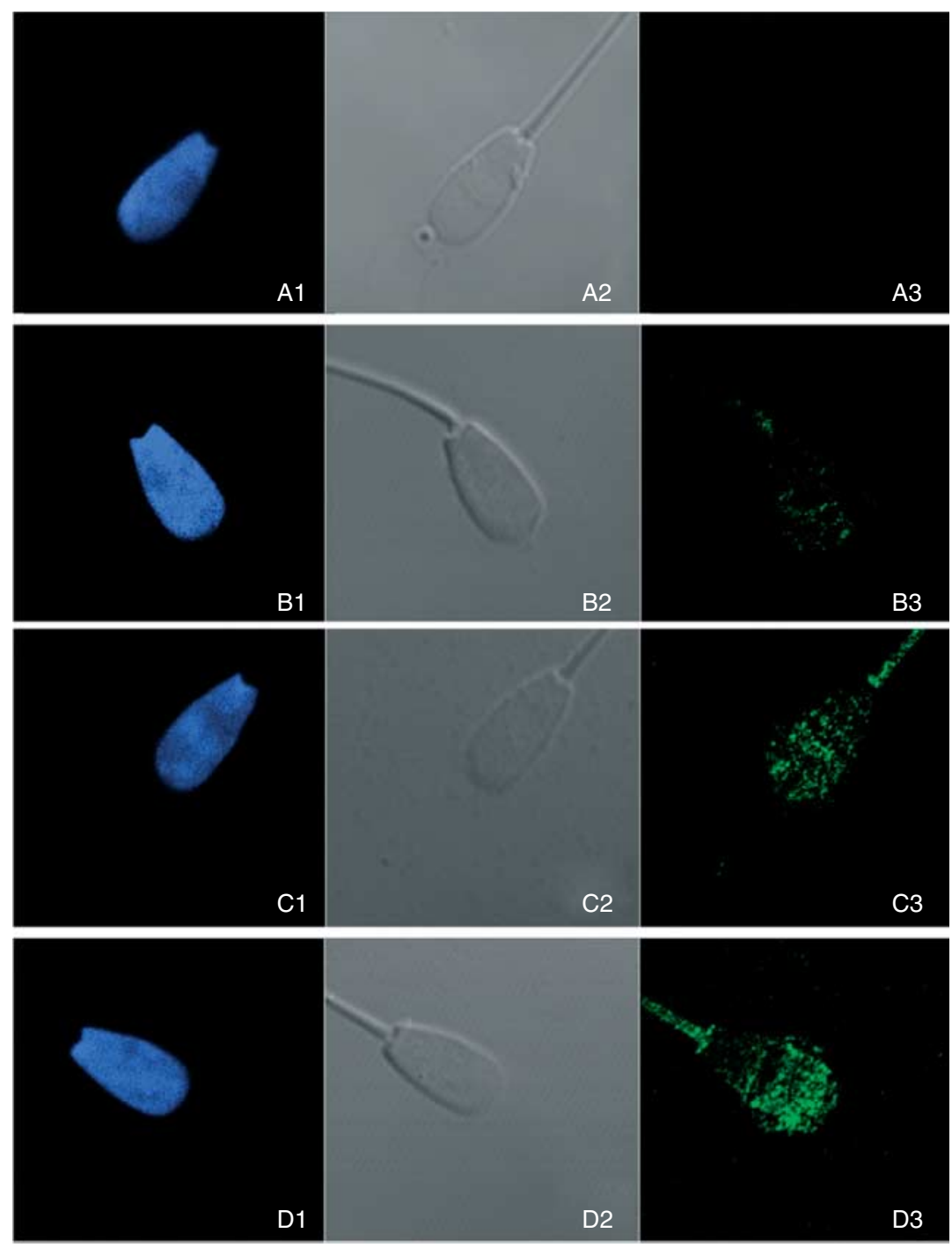

Figure 4 Immunolocalization of histones in bovine sperm cells. (A1, B1, C1 and D1) DNA stained with DAPI (blue) in a bull sperm cell; (A2, B2, C2 and D2) bright-field images; (A3, B3, C3 and D3) histones stained with DyLight 488-conjugated secondary antibody (green) in a bull sperm cell. (A3) negative control sperm cell incubated with only the secondary antibody; (B3) sperm cell with a low level of histone fluorescence; (C3) sperm cell with a medium level of histone fluorescence; and (D3) sperm cell with a high level of histone fluorescence. that histone-rich regions of the paternal genome contain genes related to embryonic development (Hammoud et al. 2009). Therefore, paternal histones can play a significant role in the evaluation of male fertility and consequently during the early development of embryos. Our hypothesis was that bull fertility was associated with histone retention in sperm cells. In order to test this hypothesis, we carried out a study evaluating sperm chromatin condensation by staining the retained and accessible histones with $\mathrm{ANBL}$ and determining the expression of specific histones $(\mathrm{H} 2 \mathrm{~B}, \mathrm{H} 3.3$, and $\mathrm{H} 4)$ in the sperm cells of bulls with varying fertility. Additionally, a computational biology procedure was performed using an online database to show the extent of conservation of the histone proteins among mammals. The ANBL test was used to stain sperm histones to determine the abnormal reduction of sperm chromatin condensation or immaturity (Hammadeh et al. 1996, Chioccarelli et al. 2010, Sati \& Huszar 2013).
Based on the ANBL test results, we conclude that overall abnormal chromatin condensation associated with abnormal retention or accessibility of sperm histones is related to bull fertility. The percentage of spermatozoa stained by ANBL was higher in the LF group than in the HF group $(P<0.0001)$. The majority of studies using the ANBL test have been conducted in humans, suggesting its predictive value for male fertility (Auger et al. 1990, Hammadeh et al. 2001). Relatively few studies have examined the association of the ANBL test and bull fertility (Vieytes et al. 2008). Among the species, the percentage of ANBL-positive sperm cells has been found to be variable, such as $1 \%$ in mice (Shokri et al. 2013), $10 \%$ in cats (Hingst et al. 1995), $10 \%$ in rabbits (Steger et al. 2005), and $50 \%$ in roosters (Santiago-Moreno et al. 2009). In bulls, the percentage of ANBL-stained sperm cells was $1-10 \%$, which was associated with sperm chromatin instability and DNA damage (Khalifa et al. 2008, Mukhopadhyay et al. 2011). 
Table 2 Immunocytochemical analysis of sperm histones of high- and low-fertility bulls. Percentage (\%), total fluorescence intensity, and area of decondensed sperm head $\left(\mu \mathrm{m}^{2}\right)$ in sperm cells with low, medium, and high levels of histone signals. The results are expressed as means (S.D. and S.E.M.).

\begin{tabular}{lcc}
\hline Parameters & Low-fertility bulls & High-fertility bulls \\
\hline Spermatozoa with low level of histone signals & 71 & 78 \\
$\quad$ Percentage $(\%)$ & $1.77 \times 10^{6}(0.76,0.09)$ & $1.97 \times 10^{6}(0.47,0.05)$ \\
$\quad$ Total fluorescence intensity & $58.70(8.38,0.99)$ & $58.66(7.06,0.80)$ \\
$\quad$ Area of decondensed sperm head $\left(\mu \mathrm{m}^{2}\right)$ & 24 & 17 \\
Spermatozoa with medium level of histone signals & $4.26 \times 10^{6}(0.77,0.16)$ & $4.27 \times 10^{6}(0.63,0.15)$ \\
$\quad$ Percentage $(\%)$ & $67.05(9.30,1.90)$ & $54.25(6.98,1.69)$ \\
$\quad$ Total fluorescence intensity & 5 & 5 \\
$\quad$ Area of decondensed sperm head $\left(\mu \mathrm{m}^{2}\right)$ & $5.37 \times 10^{6}(1.03,0.46)$ & $6.75 \times 10^{6}(0.57,0.25)$ \\
Spermatozoa with a high level of histone signals & $65.87(9.53,4.26)$ & $63.53(8.45,3.78)$ \\
$\quad$ Percentage $(\%)$ & & \\
$\quad$ Total fluorescence intensity & & \\
Area of decondensed sperm head $\left(\mu \mathrm{m}^{2}\right)$ &
\end{tabular}

Our results with a limited significant difference between the two groups could also be an indicator of inefficient spermatogenesis in LF bulls.

Our evaluation based on immunoblotting did not show any statistical association between the specific histones $(\mathrm{H} 2 \mathrm{~B}, \mathrm{H} 3.3$, and $\mathrm{H} 4)$ and bull fertility. However, we found different sperm populations with regard to the intensity of histone signals (low, medium, and high) (Fig. 4 and Table 2). We also observed a positive correlation between the area of decondensed sperm head and the signal intensities of histones $(P<0.0001)$. Considering that protamines are essential for the compaction of sperm chromatin, insufficient replacement of histones by protamines can reduce the level of chromatin condensation (Carrell et al. 2007). Higher levels of histone retention have been shown be associated with low chromatin condensation, which is believed to influence the size of the sperm head following the decondensation step (Kazerooni et al. 2009). Additionally, a study in bulls has demonstrated that DNA damage is related to sperm head abnormalities such as sperm shape and sperm head size (Enciso et al. 2011). In our study, the majority of spermatozoa displayed a low level of histone retention $(71 \%$ in the LF bulls and $78 \%$ in the HF bulls), confirming the results obtained from the ANBL test. Scattering of the immunofluorescence signals from histones displayed a punctuated variation in the sperm head (Fig. 4); this pattern was also similar to that reported in previous experiments in swines (Flores et al. 2011) and humans (Zhang et al. 2006). Additionally, one of the few immunocytochemical studies conducted on bull sperm chromatin has demonstrated that histones are also located in the perinuclear theca (Tovich \& Oko 2003). This result is consistent with our findings, where we observed that the histone signals were mainly present in the pre-equatorial region of the sperm head. Histone proteins can also be present in the cytoplasm or be associated with the mitochondria in animal cells (Johnson et al. 2007, Kutsyi 2009, Choi et al. 2011, Cascone et al. 2012); these findings can justify the histone signals observed in the sperm midpiece in our study.
Based on our immunoblotting results, we report that there was no difference in the expressions of sperm histones $(\mathrm{H} 2 \mathrm{~B}, \mathrm{H} 3.3$, and $\mathrm{H} 4)$ between the LF and $\mathrm{HF}$ bulls (Fig. 3), although spermatozoa with increased histone retention (positive to ANBL) were abundant in the LF bulls. Since the percentage of spermatozoa stained by the ANBL dye was $<2 \%$ in both the groups, this divergence may not be sufficient to significantly affect the expressions of histones measured by western blotting between the two groups. An abnormal ratio of histones to protamines in spermatozoa has been claimed to negatively affect sperm chromatin. For example, Hammoud et al. (2011) suggested that histone retention was the main reason for different localizations of histones in the sperm cells of fertile men compared with their infertile counterparts. Moreover, subfertile men with increased levels of spermatozoa stained by ANBL displayed qualitative alterations of histones related to acetylation sites in their sperm cells (Paradowska et al. 2012). The causes of excessive histone retention in sperm cells are still unclear, but the changes in testosterone and FSH levels and molecular defects might be among the contributing factors (Gill-Sharma et al. 2012). Meyer-Ficca et al. (2009, 2011) reported that the deficiency of poly(ADP-ribose) glycohydrolase an enzyme playing a role in DNA repair during spermatogenesis - in a subfertile phenotype increased the levels of phosphorylated H2AFX as well as of abnormal retention of the core histones in mouse sperm cells.

Using bioinformatic analysis, we demonstrated that $\mathrm{H} 3.3$ and $\mathrm{H} 4$ proteins were identical among bulls, mice and humans, while $\mathrm{H} 2 \mathrm{~B}$ was mostly conserved between bulls and humans compared with their mouse counterparts. These results suggest that $\mathrm{H} 3.3$ and $\mathrm{H} 4$ proteins might also be functionally identical among the species. However, we suggest here that $\mathrm{H} 2 \mathrm{~B}$ variants might have different functions among mammals. Bovine models are commonly used in diverse areas of reproductive science such as embryo cryopreservation (Huang et al. 2007), genetic tests (Almodin et al. 2005), and sperm cytotoxic assays (Cesari et al. 2007). Because valuable fertility data 
are available from the cattle Al industry (Dejarnette et al. 2004), the bull is a suitable model for studies related to genetic and epigenetic aspects of male fertility. The AI centers not only carry out analyses of more than 100 inseminations for each male, but also distribute the males in distinct levels of fertility instead of only classifying them as fertile and infertile phenotypes. In addition, techniques for in vitro production of bovine embryos are well established and are suitable for evaluating the impact of male epigenome on mammalian embryonic development (Machaty et al. 2012). In this study, we also showed the conservation and evolutionary relationships of the histone proteins among bulls, mice and humans in order to further the value of bull sperm cells for studies on the integrity of mammalian sperm chromatin.

This study is the first to evaluate the differences in bull fertility as related to the expression of sperm histones. The small sample size used for the immunofluorescence analysis limited the statistical power needed to detect significant differences within the two groups. However, these results showed variations among the sperm populations that can be furthered using a large sample size for clinical or diagnostic purposes (Fig. 4). Although PTMs in histones modulate the sperm epigenome, our study did not focus on these traits (Jenkis \& Carrell 2012). Thus, a qualitative analysis of PTMs in histones of bulls can yield new perspectives to better understand epigenetic regulations affecting sire fertility. Despite using the current semen analysis methods, the prediction of bull fertility is still far from the demands of the cattle industry. In humans, the paternal histone contribution to zygotes has been examined, which demonstrated a possible influence of the male epigenome on embryonic development (van der Heijden et al. 2008). In this context, the evaluation of paternal epigenome can yield new perspectives for both producers and consumers in bull selection. In conclusion, our results showed that bull fertility was associated with chromatin condensation status changed by histone retention in a sperm population. We did not find any relationship between the expression levels of specific histones (H2B, H3.3, and $\mathrm{H} 4$ ) and bull fertility. In addition, using immunofluorescence analysis, we demonstrated distinct sperm populations with regard to nucleohistone signals.

\section{Supplementary data}

This is linked to the online version of the paper at http://dx.doi. org/10.1530/REP-12-0399.

\section{Declaration of interest}

The authors declare that there is no conflict of interest that could be perceived as prejudicing the impartiality of the research reported.

\section{Funding}

This study was funded in part by the Mississippi Agricultural and Forestry Experiment Station, Alta Genetic, Inc., CNPq (Brazil) and CAPES-FULBRIGHT Program.

\section{Acknowledgements}

The authors thank Ms Amanda Lawrence and Mr William Monroe for their technical assistance with the immunocytochemistry and fluorescent microscopy experiments.

\section{References}

Agarwal A \& Said TM 2003 Role of sperm chromatin abnormalities and DNA damage in male infertility. Human Reproduction Update 9 331-345. (doi:10.1093/humupd/dmg027)

Almodin CG, Moron AF, Kulay L Jr, Minguetti-Câmara VC, Moraes AC \& Torloni MR 2005 A bovine protocol for training professionals in preimplantation genetic diagnosis using polymerase chain reaction. Fertility and Sterility 84 895-899. (doi:10.1016/j.fertnstert.2005.02.051)

Auger J, Mesbah M, Huber C \& Dadoune JP 1990 Aniline blue staining as a marker of sperm chromatin defects associated with different semen characteristics discriminates between proven fertile and suspected infertile men. International Journal of Andrology 13 452-462. (doi:10.1111/j.1365-2605.1990.tb01052.x)

Blaschek M, Kaya A, Zwald N, Memili E \& Kirkpatrick BW 2011 A wholegenome association analysis of noncompensatory fertility in Holstein bulls. Journal of Dairy Science 94 4695-4699. (doi:10.3168/jds.20103728)

Brykczynska U, Hisano M, Erkek S, Ramos L, Oakeley EJ, Roloff TC, Beisel C, Schubeler D, Stadler MB \& Peters AH 2010 Repressive and active histone methylation mark distinct promoters in human and mouse spermatozoa. Nature Structural \& Molecular Biology 17 679-687. (doi:10.1038/nsmb.1821)

Carrell DT, Emery BR \& Hammoud S 2007 Altered protamine expression and diminished spermatogenesis: what is the link? Human Reproduction Update 13 313-327. (doi:10.1093/humupd/dml057)

Cascone A, Bruelle C, Lindholm D, Bernardi P \& Eriksson O 2012 Destabilization of the outer and inner mitochondrial membranes by core and linker histones. PLOS ONE 7 e35357. (doi:10.1371/journal.pone. 0035357)

Cesari A, Falcinelli AL, Mendieta JR, Pagano MR, Mucci N, Daleo GR \& Guevara MG 2007 Potato aspartic proteases (StAPs) exert cytotoxic activity on bovine and human spermatozoa. Fertility and Sterility $\mathbf{8 8}$ 1248-1255. (doi:10.1016/j.fertnstert.2007.02.008)

Chang YM, Gianola D, Heringstad B \& Klemetsdal G 2004 Effects of trait definition on genetic parameter estimates and sire evaluation for clinical mastitis with threshold models. Animal Science 79 355-363.

Chioccarelli T, Cacciola G, Altucci L, Lewis SE, Simon L, Ricci G, Ledent C, Meccariello R, Fasano S, Pierantoni R et al. 2010 Cannabinoid receptor 1 influences chromatin remodeling in mouse spermatids by affecting content of transition protein 2 mRNA and histone displacement. Endocrinology 115 5017-5029. (doi:10.1210/en.2010-0133)

Choi Y-S, Hoon Jeong J, Min H-K, Jung H-J, Hwang D, Lee S-W \& Kim Pak Y 2011 Shot-gun proteomic analysis of mitochondrial D-loop DNA binding proteins: identification of mitochondrial histones. Molecular BioSystems 7 1523-1536. (doi:10.1039/c0mb00277a)

Correa JR, Pace MM \& Zavos PM 1997 Relationship among frozen-thawed sperm characteristics assessed via the routine semen analysis, sperm functional tests and fertility of bulls in an artificial insemination program. Theriogenology 48 721-731. (doi:10.1016/S0093-691X(97)00296-3)

Dadoune JP 1995 The nuclear status of human sperm cells. Micron 26 323-345. (doi:10.1016/0968-4328(95)00007-0)

Dadoune JP 2003 Expression of mammalian spermatozoal nucleoproteins. Microscopy Research and Technique 61 56-75. (doi:10.1002/jemt. 10317) 
Dadoune JP, Mayaux MJ \& Guihard-Moscato ML 1988 Correlation between defects in chromatin condensation of human spermatozoa stained by aniline blue and semen characteristics. Andrologia 20 211-217. (doi:10.1111/j.1439-0272.1988.tb01058.x)

D'Amours O, Frenette G, Fortier M, Leclerc P \& Sullivan R 2010 Proteomic comparison of detergent-extracted sperm proteins from bulls with different fertility indexes. Reproduction 139 545-556. (doi:10.1530/ REP-09-0375)

Dejarnette JM, Marshall CE, Lenz RW, Monke DR, Ayars WH \& Sattler CG 2004 Sustaining the fertility of artificially inseminated dairy cattle: the role of the artificial insemination industry. Journal of Dairy Science $\mathbf{8 7}$ (Supplement) E93-E104. (doi:10.3168/jds.S0022-0302(04)70065-X)

D'Occhio MJ, Hengstberger KJ \& Johnston SD 2007 Biology of sperm chromatin structure and relationship to male fertility and embryonic survival. Animal Reproduction Science 101 1-17. (doi:10.1016/j.anireprosci.2007.01.005)

Enciso M, Cisale H, Johnston SD, Sarasa J, Fernández JL \& Gosálvez J 2011 Major morphological sperm abnormalities in the bull are related to sperm DNA damage. Theriogenology 76 23-32. (doi:10.1016/j.theriogenology.2010.12.034)

Fischle W, Wang Y, Jacobs SA, Kim Y, Allis CD \& Khorasanizadeh S 2003 Molecular basis for the discrimination of repressive methyl-lysine marks in histone $\mathrm{H} 3$ by Polycomb and HP1 chromodomains. Genes and Development 17 1870-1881. (doi:10.1101/gad.1110503)

Flores E, Ramió-Lluch L, Bucci D, Fernández-Novell JM, Peña A \& Rodríguez-Gil JE 2011 Freezing-thawing induces alterations in histone H1-DNA binding and the breaking of protein-DNA disulfide bonds in boar sperm. Theriogenology 76 1450-1464. (doi:10.1016/j.theriogenology.2011.05.039)

Franken DR, Franken CJ, de la Guerre H \& de Villiers A 1999 Normal sperm morphology and chromatin packaging: comparison between aniline blue and chromomycin A3 staining. Andrologia 31 361-366. (doi:10.1046/ j.1439-0272.1999.00290.x)

García-Macías V, De Paz P, Martinez-Pastor F, Álvarez M, Gomes-Alves S, Bernardo J, Anel E \& Anel L 2007 DNA fragmentation assessment by flow cytometry and Sperm-Bos-Halomax (bright-field microscopy and fluorescence microscopy) in bull sperm. International Journal of Andrology 30 88-98. (doi:10.1111/j.1365-2605.2006.00723.x)

Gatewood JM, Cook GR, Balhorn R, Schmid CW \& Bradbury EM 1990 Isolation of four core histones from human sperm chromatin representing a minor subset of somatic histones. Journal of Biological Chemistry $\mathbf{2 6 5}$ 20662-20666.

Gill-Sharma MK, Choudhuri J, Ansari MA \& D'Souza S 2012 Putative molecular mechanism underlying sperm chromatin remodelling is regulated by reproductive hormones. Clinical Epigenetics 423. (doi:10.1186/1868-7083-4-23)

Hales BF, Grenier L, Lalancette C \& Robaire B 2011 Epigenetic programming: from gametes to blastocyst. Birth Defects Research. Part A, Clinical and Molecular Teratology 91 652-665. (doi:10.1002/ bdra.20781)

Hammadeh ME, Al-Hasani S, Stieber M, Rosenbaum P, Küpker D, Diedrich K \& Schmidt W 1996 The effect of chromatin condensation (aniline blue staining) and morphology (strict criteria) of human spermatozoa on fertilization, cleavage and pregnancy rates in an intracytoplasmic sperm injection program. Human Reproduction $\mathbf{1 1}$ 2468-2471. (doi:10.1093/oxfordjournals.humrep.a019139)

Hammadeh ME, Zeginiadov T, Rosenbaum P, Georg T, Schmidt W \& Strehler E 2001 Predictive value of sperm chromatin condensation (aniline blue staining) in the assessment of male fertility. Archives of Andrology 46 99-104. (doi:10.1080/01485010151093958)

Hammoud SS, Nix DA, Zhang H, Purwar J, Carrell DT \& Cairns BR 2009 Distinctive chromatin in human sperm packages genes for embryo development. Nature 460 473-478. (doi:10.1038/nature08162)

Hammoud SS, Nix DA, Hammoud AO, Gibson M, Cairns BR \& Carrell DT 2011 Genome-wide analysis identifies changes in histone retention and epigenetic modifications at developmental and imprinted gene loci in the sperm of infertile men. Human Reproduction 26 2558-2569. (doi:10.1093/humrep/der192)

van der Heijden GW, Derijck AA, Ramos L, Giele M, van der Vlag J \& de Boer $\mathbf{P} 2006$ Transmission of modified nucleosomes from the mouse male germline to the zygote and subsequent remodeling of paternal chromatin. Developmental Biology 298 458-469. (doi:10.1016/j.ydbio. 2006.06.051)

van der Heijden G, Ramos L, Baart E, van den Berg I, Derijck A, van der Vlag J, Martini E \& de Boer P 2008 Sperm-derived histones contribute to zygotic chromatin in humans. BMC Developmental Biology 834. (doi:10.1186/1471-213X-8-34)

Hingst O, Blottner S \& Franz C 1995 Chromatin condensation in cat spermatozoa during epididymal transit as studied by aniline blue and acridine orange staining. Andrologia 27 275-279. (doi:10.1111/j.14390272.1995.tb01105.x)

Huang JY, Chung J-T, Tan SL \& Chian R-C 2007 High survival and hatching rates following vitrification of embryos at blastocyst stage: a bovine model study. Reproductive Biomedicine Online 14 464-470. (doi:10.1016/S1472-6483(10)60894-2)

Januskauskas A, Gil J, Söderquist L, Håård MG, Håård MC, Johannisson A \& Rodriguez-Martinez H 1999 Effect of cooling rates on post-thaw sperm motility, membrane integrity, capacitation status and fertility of dairy bull semen used for artificial insemination in Sweden. Theriogenology $\mathbf{5 2}$ 641-658. (doi:10.1016/S0093-691X(99)00159-4)

Jenkins TG \& Carrell DT 2012 The sperm epigenome and potential implications for the developing embryo. Reproduction 143 727-734. (doi:10.1530/REP-11-0450)

Johnson DT, Harris RA, French S, Blair PV, You J, Bemis KG, Wang M \& Balaban RS 2007 Tissue heterogeneity of the mammalian mitochondrial proteome. American Journal of Physiology. Cell Physiology 292 C689-C697. (doi:10.1152/ajpcell.00108.2006)

Kazerooni T, Asadi N, Jadid L, Kazerooni M, Ghanadi A, Ghaffarpasand F, Kazerooni Y \& Zolghadr J 2009 Evaluation of sperm's chromatin quality with acridine orange test, chromomycin A3 and aniline blue staining in couples with unexplained recurrent abortion. Journal of Assisted Reproduction and Genetics 26 591-596. (doi:10.1007/s10815-0099361-3)

Khalifa TAA, Rekkas CA, Lymberopoulos AG, Sioga A, Dimitriadis I \& Papanikolaou T 2008 Factors affecting chromatin stability of bovine spermatozoa. Animal Reproduction Science 104 143-163. (doi:10.1016/ j.anireprosci.2007.02.019)

Kleiman SE, Bar-Shira Maymon B, Hauser R, Botchan A, Paz G, Yavetz H \& Yogev L 2008 Histone H4 acetylation and AZFc involvement in germ cells of specimens of impaired spermatogenesis. Fertility and Sterility $\mathbf{8 9}$ 1728-1736. (doi:10.1016/j.fertnstert.2007.05.068)

Kutsyi MP 2009 Histones induce the release of apoptogenic factors from liver mitochondria. Biological Bulletin 36 328-332. (doi:10.1134/ S1062359009040025)

de Lamirande E, San Gabriel MC \& Zini A 2012 Human sperm chromatin undergoes physiological remodeling during in vitro capacitation and acrosome reaction. Journal of Andrology 33 1025-1035. (doi:10.2164/ jandrol.111.015982)

Li Y, Lalancette C, Miller D \& Krawetz SA 2008 Characterization of nucleohistone and nucleoprotamine components in the mature human sperm nucleus. Asian Journal of Andrology 10 535-541. (doi:10.1111/ j.1745-7262.2008.00410.x)

Machaty Z, Peippo J \& Peter A 2012 Production and manipulation of bovine embryos: techniques and terminology. Theriogenology 78 937-950. (doi:10.1016/j.theriogenology.2012.04.003)

Meyer-Ficca ML, Lonchar J, Credidio C, Ihara M, Li Y, Wang ZQ \& Meyer RG 2009 Disruption of poly(ADP-ribose) homeostasis affects spermiogenesis and sperm chromatin integrity in mice. Biology of Reproduction 81 46-55. (doi:10.1095/biolreprod.108.075390)

Meyer-Ficca ML, Ihara M, Lonchar JD, Meistrich ML, Austin CA, Min W, Wang ZQ \& Meyer RG 2011 Poly(ADP-ribose) metabolism is essential for proper nucleoprotein exchange during mouse spermiogenesis. Biology of Reproduction 84 218-228. (doi:10.1095/biolreprod.110. 087361)

Miller D, Brinkworth M \& Iles D 2010 Paternal DNA packaging in spermatozoa: more than the sum of its parts? DNA, histones, protamines and epigenetics Reproduction 139 287-301. (doi:10.1530/REP-09-0281)

Mito Y, Henikoff JG \& Henikoff S 2005 Genome-scale profiling of histone H3.3 replacement patterns. Nature Genetics 37 1090-1097. (doi:10.1038/ng1637) 
Motoishi M, Goto K, Tomita K, Ookutsu S \& Nakanishi Y 1996 Decondensation of bull and human sperm nuclei by dithiothreitol and/or heparin. Journal of Reproduction and Development 42 7-13. (doi:10.1262/jrd.42.7)

Mukhopadhyay CS, Gupta AK, Yadav BR, Chauhan IS, Gupta A, Mohanty TK \& Raina VS 2011 Effect of cryopreservation on sperm chromatin integrity and fertilizing potential in bovine semen. Livestock Science 136 114-121. (doi:10.1016/j.livsci.2010.08.010)

Paradowska AS, Miller D, Spiess AN, Vieweg $M$, Cerna $M$, Dvorakova-Hortova K, Bartkuhn M, Schuppe HC, Weidner W \& Steger K 2012 Genome wide identification of promoter binding sites for H4K12ac in human sperm and its relevance for early embryonic development. Epigenetics 7 1057-1070. (doi:10.4161/ epi.21556)

Peddinti D, Nanduri B, Kaya A, Feugang JM, Burgess SC \& Memili E 2008 Comprehensive proteomic analysis of bovine spermatozoa of varying fertility rates and identification of biomarkers associated with fertility. BMC Systems Biology 2 19. (doi:10.1186/1752-0509-2-19)

Prigent C \& Dimitrov S 2003 Phosphorylation of serine 10 in histone H3, what for? Journal of Cell Science 116 3677-3685. (doi:10.1242/jcs. 00735)

Puglisi R, Pozzi A, Foglio L, Spanò M, Eleuteri P, Grollino MG, Bongioni G \& Galli A 2012 The usefulness of combining traditional sperm assessments with in vitro heterospermic insemination to identify bulls of low fertility as estimated in vivo. Animal Reproduction Science 132 17-28. (doi:10.1016/j.anireprosci.2012.04.006)

Rajender S, Avery K \& Agarwal A 2011 Epigenetics, spermatogenesis and male infertility. Mutation Research 727 62-71. (doi:10.1016/j.mrrev. 2011.04.002)

Saitou N \& Nei M 1987 The neighbor-joining method: a new method for reconstructing phylogenetic tress. Molecular Biology and Evolution 4 406-425.

Santiago-Moreno J, Castaño C, Coloma MA, Gómez-Brunet A, Toledano-Díaz A, López-Sebastián A \& Campo JL 2009 Use of the hypo-osmotic swelling test and aniline blue staining to improve the evaluation of seasonal sperm variation in native Spanish free-range poultry. Poultry Science 88 2661-2669. (doi:10.3382/ps.2008-00542)

Sati L \& Huszar G 2013 Methodology of aniline blue staining of chromatin and the assessment of the associated nuclear and cytoplasmic attributes in human sperm. Methods in Molecular Biology 927 425-436. (doi:10. 1007/978-1-62703-038-0_36)

Shokri S, Hemadi M, Bayat G, Bahmanzadeh M, Jafari-Anarkooli I \& Mashkani B 2013 Combination of running exercise and high dose of anabolic androgenic steroid, nandrolone decanoate, increases protamine deficiency and DNA damage in rat spermatozoa. Andrologia [in press]. (doi:10.1111/and.12061)

Simon L, Castillo J, Oliva R \& Lewis SE 2011 Relationships between human sperm protamines, DNA damage and assisted reproduction outcomes. Reproductive Biomedicine Online 23 724-734. (doi:10.1016/j.rbmo. 2011.08.010)

Silva PFN \& Gadella BM 2006 Detection of damage in mammalian sperm cells. Theriogenology 65 958-978. (doi:10.1016/j.theriogenology.2005. 09.010)
Sonnack V, Failing K, Bergmann M \& Steger K 2002 Expression of hyperacetylated histone $\mathrm{H} 4$ during normal and impaired human spermatogenesis. Andrologia 34 384-390. (doi:10.1046/j.1439-0272. 2002.00524.x)

Steger K, Slavov M, Failing K, Weidner W \& Bergmann M 2005 Effect of vasectomy on sperm nuclear chromatin condensation in the rabbit. Journal of Andrology 26 289-295.

Steilmann C, Paradowska A, Bartkuhn M, Vieweg M, Schuppe H-C, Bergmann M, Kliesch S, Weidner W \& Steger K 2011 Presence of histone $\mathrm{H} 3$ acetylated at lysine 9 in male germ cells and its distribution pattern in the genome of human spermatozoa. Reproduction, Fertility, and Development 23 997-1011. (doi:10.1071/RD10197)

Struhl K 1998 Histone acetylation and transcriptional regulatory mechanisms. Genes and Development 12 599-606. (doi:10.1101/gad. 12.5.599)

Tovich PR \& Oko RJ 2003 Somatic histones are components of the perinuclear theca in bovine spermatozoa. Journal of Biological Chemistry 278 32431-32438. (doi:10.1074/jbc.M303786200)

UniProt C 2012 Reorganizing the protein space at the Universal Protein Resource (UniProt). Nucleic Acids Research 40 D71-D75. (doi:10.1093/ nar/gkr981)

Vieytes AL, Cisale HO \& Ferrari MR 2008 Relationship between the nuclear morphology of the sperm of 10 bulls and their fertility. Veterinary Record 163 625-629. (doi:10.1136/vr.163.21.625)

de Yebra L \& Oliva R 1993 Rapid analysis of mammalian sperm nuclear proteins. Analytical Biochemistry 209 201-203. (doi:10.1006/abio. 1993.1104)

Zhang X, San Gabriel M \& Zini A 2006 Sperm nuclear histone to protamine ratio in fertile and infertile men: evidence of heterogeneous subpopulations of spermatozoa in the ejaculate. Journal of Andrology 27 414-420. (doi:10.2164/jandrol.05171)

Zini A, Zhang X \& Gabriel MS 2008 Sperm nuclear histone H2B: correlation with sperm DNA denaturation and DNA stainability. Asian Journal of Andrology 10 865-871. (doi:10.1111/j.1745-7262.2008. 00415.x)

Zwald NR, Weigel KA, Chang YM, Welper RD \& Clay JS 2004a Genetic selection for health traits using producer-recorded data. I. Incidence rates, heritability estimates, and sire breeding values. Journal of Dairy Science 87 4287-4294. (doi:10.3168/jds.S0022-0302(04)73573-0)

Zwald NR, Weigel KA, Chang YM, Welper RD \& Clay JS 2004b Genetic selection for health traits using producer-recorded data. II. Genetic correlations, disease probabilities, and relationships with existing traits. Journal of Dairy Science 87 4295-4302. (doi:10.3168/jds.S00220302(04)73574-2)

Received 9 October 2012

First decision 5 November 2012

Revised manuscript received 16 May 2013

Accepted 13 June 2013 